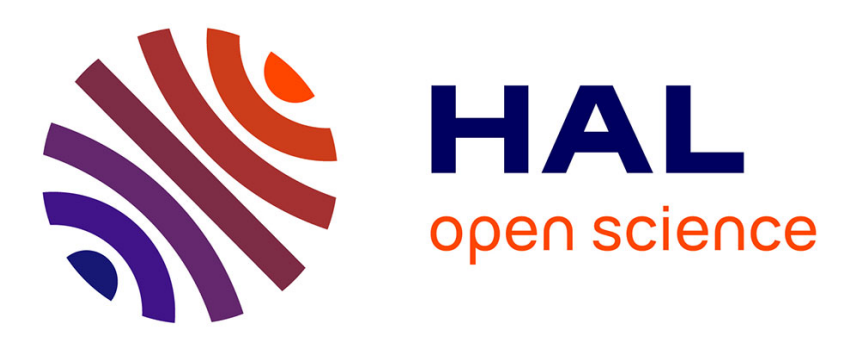

\title{
Soil Texture Effects on Surface Resistance to Bare-Soil Evaporation
}

\author{
P. Lehmann, O. Merlin, P. Gentine, D. Or
}

\section{To cite this version:}

P. Lehmann, O. Merlin, P. Gentine, D. Or. Soil Texture Effects on Surface Resistance to Bare-Soil Evaporation. Geophysical Research Letters, 2018, 45 (19), pp.10,398-10,405. 10.1029/2018GL078803 . insu-03668271

\section{HAL Id: insu-03668271 https://hal-insu.archives-ouvertes.fr/insu-03668271}

Submitted on 16 May 2022

HAL is a multi-disciplinary open access archive for the deposit and dissemination of scientific research documents, whether they are published or not. The documents may come from teaching and research institutions in France or abroad, or from public or private research centers.
L'archive ouverte pluridisciplinaire HAL, est destinée au dépôt et à la diffusion de documents scientifiques de niveau recherche, publiés ou non, émanant des établissements d'enseignement et de recherche français ou étrangers, des laboratoires publics ou privés.

$$
\text { Copyright }
$$




\section{Geophysical Research Letters}

\section{RESEARCH LETTER}

10.1029/2018GL078803

\section{Key Points:}

- Bare-soil evaporation is a nonlinear function of water content and soil texture that jointly determine capillary water supply rates to vaporization plane at the surface

- A soil type-based analytical model for predicting evaporation-induced capillary flow depth and surface resistance to evaporation was presented

- Predictions by the resistance model were in good agreement with flux tower evaporation measurements from 10 different soil types across climatic conditions

Supporting Information:

- Supporting Information S1

Correspondence to:

P. Lehmann,

peter.lehmann@env.ethz.ch

Citation:

Lehmann, P., Merlin, O., Gentine, P., \& Or, D. (2018). Soil texture effects on surface resistance to bare-soil evaporation. Geophysical Research Letters, 45, 10,398-10,405. https://doi. org/10.1029/2018GL078803

Received 16 MAY 2018 Accepted 11 SEP 2018 Accepted article online 14 SEP 2018 Published online 2 OCT 2018

\section{Soil Texture Effects on Surface Resistance to Bare-Soil Evaporation}

\author{
P. Lehmann' ${ }^{1}$, O. Merlin² iD, P. Gentine ${ }^{3}$ iD, and D. Or ${ }^{1}$ iD \\ ${ }^{1}$ Soil and Terrestrial Environmental Physics, ETH Zurich, Zurich, Switzerland, ${ }^{2}$ CESBIO, Université de Toulouse, CNES, CNRS \\ IRD, UPS, Toulouse, France, ${ }^{3}$ Department Earth and Environmental Engineering, Columbia University, New York, USA
}

\begin{abstract}
Modeling of surface energy balance and the separation of evapotranspiration to its component fluxes require quantification of evaporation from land surfaces. The nonlinear relationship between surface heat fluxes and the hydration state of soil surfaces present a challenge to remote estimation of surface evaporation rates. We study the often-overlooked role of soil properties in determining surface evaporation resistance. We present a framework for quantifying how the ratio of actual to potential evaporation rates varies with changes in surface water content for different soil textures. The model uses the evaporative characteristic length (a soil-dependent active depth of evaporation) and soil resistance to capillary flow across that region. Predictions were in good agreement with flux tower measurements of bare-soil evaporation from 10 soil textural classes. The study offers a simple and physically based method for incorporating surface evaporation resistance into land-surface models considering soil type and surface water content.
\end{abstract}

Plain Language Summary Water evaporation from soils is an important process of the hydrologic cycle and Earth surface energy balance. The evaporation rates depend on the available energy but are very sensitive as well to the capacity of the soil to retain water and to supply it to the surface where evaporation occurs. This capacity mainly depends on the size of the pores that is related to soil texture. In this letter we present a physically based model that predicts evaporation rates for different textures and soil water contents. The predictions were successfully compared with measurements from various bare-soil sites around the globe. The presented approach can be applied in land-surface models and remote sensing estimates.

\section{Introduction}

Soil evaporation is an important process affecting the global hydrological cycle and surface energy balance. Quantification of soil evaporation is required for separation of evapotranspiration to its components (transpiration, canopy interception, and evaporation) for water resource management and for better links between the water and carbon cycles (Fisher et al., 2017; Miralles et al., 2016; Wei et al., 2017). Soil evaporation nonlinearly depends on soil water content and evaporative demand, often assessed using potential evaporation rate that is a function of radiative energy input, air humidity, surface temperature, and wind velocity (Allen et al., 1998; Martens et al., 2017).

Evidence suggests that the nonlinear relation of evaporation with soil moisture varies with soil properties (Merlin et al., 2016; Wetzel \& Chang, 1987). This was already stated in the study of Budyko (1958) and Manabe (1969) introducing a "critical water content" that must be exceeded to sustain high evaporation rate and was related to soil texture-dependent field capacity (Manabe, 1969) and different soil types in different geographic regions (Budyko, 1958). However, difficulties in systematically considering effects of soil texture on surface evaporation rates led many land-surface models to ignore soil type (texture) in the estimation of surface evaporation (Phillips et al., 2017).

Part of the difficulty of incorporating a systematic approach to soil surface evaporation stems from ambiguities regarding the processes that control evaporation rates; these have been reported to include limitations related to capillary flow (Haghighi et al., 2013), vapor diffusion from receding vaporization plane (Or et al., 2013), evaporation resistance due to surface water content (Bittelli et al., 2008), and enhancement factors due to temperature gradients in the soil (Philip \& de Vries, 1957). Consequently, surface evaporation rate is often represented empirically as function of the surface water content (Lee \& Pielke, 1992; van de 
Griend \& Owe, 1994; Wallace, 1995; Yamanaka \& Yonetani, 1999) including the identification of a "critical" water content where actual evaporation rate drops below potential rate and subsequently diminishes with surface drying (Wythers et al., 1999). In a recent study on bare-soil evaporation, Merlin et al. (2016) showed that the nonlinear relationship between evaporation rate $E_{\text {surf }}$ and surface water content $\theta_{\text {surf }}$ varied systematically with soil texture across several well-instrumented sites. They proposed an empirical relationship between a critical water content (denoted as $\theta_{1 / 2}$ where actual evaporation rate $E_{\text {surf }}$ is half the potential rate $\left.E_{0}\right)$ and soil texture (clay and sand content). In this study we seek to provide a physical basis for the soil texture dependence on soil evaporation, so that the ratio $E_{\text {surf }} / E_{0}$ and the critical water content $\theta_{1 / 2}$ can be physically described for inclusion in land-surface models. The theory is based on the approach of Haghighi et al. (2013) and is explained in the following section.

\section{Effects of Soil Texture on Surface Evaporation Fluxes- Theoretical Considerations}

Studies have shown that evaporation rate $E_{\text {surf }}$ from a partially dry soil surface depends on soil properties and on atmospheric conditions (Shahraeeni et al., 2012; Suzuki \& Maeda, 1968); thus, it is convenient to normalize $E_{\text {surf }}$ by potential evaporation rate $E_{0}$ from a similar fully wet surface (i.e., with same aerodynamic resistance). In the simplest scenario of a flat homogenous surface, the potential evaporation rate $E_{0}$ is determined by the vertical vapor pressure gradient across a near-surface boundary layer of thickness $\delta$ :

$$
E_{0}=\frac{D_{\text {air }}}{\delta} \cdot \frac{M_{\mathrm{W}}}{\Re \cdot T} \frac{\left(p_{\text {sat }}-p_{\text {air }}\right)}{\rho_{\text {water }}}
$$

with vapor diffusion coefficient in air $D_{\text {air }}$ molar water mass $M_{\mathrm{w}}$, water density $\rho_{\text {water }}$ gas constant $\mathfrak{R}$, vapor pressure $P_{\text {air }}$ in air above boundary layer with temperature $T$, and saturated vapor pressure at surface $P_{\text {sat }}$. We rewrite equation (1) using the formulation of resistance:

$$
E_{0}=\frac{1}{R_{\mathrm{BL}}} \cdot \frac{M_{\mathrm{W}}}{\mathfrak{R} \cdot T} \frac{\left(p_{\text {sat }}-p_{\text {air }}\right)}{\rho_{\text {water }}}
$$

with

$$
R_{\mathrm{BL}}=\frac{\delta}{D_{\text {air }}}
$$

with aerodynamic or boundary layer resistance $R_{\mathrm{BL}}$. For a partially dry surface with mean water content $\theta_{\text {surf, }}$ the evaporation rate is expected to be further reduced by the decreased evaporating area defined by resistance term $R_{\text {shell }}$ (Shahraeeni et al., 2012; Zhang et al., 2015) and by limited water supply from subsurface soil defined by resistance term $R_{\text {soil }}$ (Haghighi et al., 2013). We thus formulate a model for $E_{\text {surf }}$ similar to the approach of Haghighi et al. (2013) and Decker et al. (2017) by expressing surface evaporation rates as

$$
E_{\text {surf }}=\frac{1}{R_{\mathrm{BL}}+R_{\text {shell }}+R_{\text {soil }}} \cdot \frac{M_{\mathrm{W}}}{R \cdot T} \frac{\left(P_{\text {sat }}-P_{\text {air }}\right)}{\rho_{\text {water }}}
$$

The vapor shell resistance $R_{\text {shell }}$ is due to the configurational resistance to diffusion through vapor shells forming around evaporating pores (diffusion in 3-D from the evaporating pores across a hemisphere; see supporting information S1 for derivation; Bange, 1953; Schlünder, 1988) expressed as

$$
R_{\text {shell }}=\frac{1}{D_{\text {air }}} \frac{r_{\text {pore }}\left(\pi-2 \sqrt{\theta_{\text {surf }}}\right)}{4 \theta_{\text {surf }}}
$$

with typical pore size $r_{\text {pore }}$ (its value is explained in supporting information S1). For viscous flow and the definition of a soil resistance term $R_{\text {soil, }}$ we use Buckingham-Darcy capillary flux density $J_{\mathrm{W}}$ :

$$
J_{\mathrm{W}}=K_{\mathrm{eff}} \frac{\Delta H}{\Delta z}
$$

with effective hydraulic conductivity $K_{\text {eff }}$ representative for the region between the wet subsurface (from where water is supplied) and the dry surface, and pressure head difference $\Delta H$ acting across a soil layer of thickness $\Delta z$. Haghighi et al. (2013) showed that for low surface water contents $\theta_{\text {surf }}$ the value $4 K\left(\theta_{\text {surf }}\right)$ was 
a good estimate for $K_{\text {eff }}$. To express the soil resistance in a form comparable to the boundary layer resistance term we define

$$
J_{\mathrm{W}}=4 K\left(\theta_{\text {surf }}\right) \frac{\Delta H}{\Delta z}=\frac{1}{R_{\text {soil }}} \cdot \frac{M_{\mathrm{W}}}{\mathfrak{R} \cdot T} \frac{\left(P_{\text {sat }}-P_{\text {air }}\right)}{P_{\text {water }}} \rightarrow R_{\text {soil }}=\frac{1}{4 K\left(\theta_{\text {surf }}\right) \frac{\Delta H}{\Delta z}} \cdot \frac{M_{\mathrm{W}}}{\mathfrak{R} \cdot T} \frac{\left(P_{\text {sat }}-P_{\text {air }}\right)}{\rho_{\text {water }}}
$$

Note that the two resistance terms, $R_{\text {soil }}$ (equation (6)) and $R_{\text {shell }}$ (equation (4)), are not independent but are correlated and related to the surface water content $\theta_{\text {surf }}$ (see as well supporting information S1; Bange, 1953; Guarracino, 2007; Schlünder, 1988). Haghighi et al. (2013) assumed a gradient of $\Delta H / \Delta z=1$, whereas evidence suggests that this choice may underestimate capillary pressure gradients near the surface. To better represent this vertical capillary gradient, we expand the derivations of Lehmann et al. (2008) that expressed the driving capillary pressure difference as a "gravity length" $L_{\mathrm{G}}$ (difference between air entry value $h_{\mathrm{b}}$ and critical capillary pressure head $h_{\mathrm{c}}$ at which hydraulic flow paths become disconnected). We apply the parametric model of van Genuchten (1980) where the critical capillary pressure head and gravity length are expressed analytically as

$$
\begin{gathered}
h_{\mathrm{C}}=\frac{1}{\alpha}\left(\frac{n-1}{n}\right)^{\frac{1-2 n}{n}} \\
L_{\mathrm{G}}=h_{\mathrm{C}}-h_{\mathrm{b}}=\frac{1}{\alpha(n-1)}\left(\frac{2 n-1}{n}\right)^{\frac{2 n-1}{n}}\left(\frac{n-1}{n}\right)^{\frac{1-n}{n}}
\end{gathered}
$$

with parameters $\alpha, n$ defining the shape of the relationship between capillary pressure head $h$ and water content $\theta$. This capillary pressure gradient is dissipated along a characteristic length $L_{C}$ due to capillary flow against gravity and intrinsic viscous resistance (that varies with soil texture and water content) that supplies the atmospheric evaporation demand $E_{0}$ :

$$
L_{C}=\frac{L_{G}}{1+E_{0} / 4 K\left(h_{C}\right)}
$$

The effective unsaturated hydraulic conductivity was estimated as $4 K\left(h_{\mathrm{C}}\right)$, with the hydraulic conductivity expressed as a function of the capillary pressure $h_{\mathrm{C}}$. The capillary gradient that drives flow to the evaporating surface is thus

$$
\frac{\Delta H}{\Delta z}=\frac{L_{G}}{L_{C}}=1+E_{0} / 4 K\left(h_{C}\right)
$$

Inserting this gradient into equation (6) enables (closed form) representation of surface evaporation resistances $R_{\text {shell }}$ and $R_{\text {soil, }}$ and their magnitudes relative to the boundary layer resistance $R_{\mathrm{BL}}$. These resistances are illustrated in Figure 1a for two soil textural classes, indicating that for unsaturated conditions soil evaporation resistance is dominated by limitations to capillary flow $R_{\text {soil, }}$ and the surface water content effects on the vapor shell resistance $R_{\text {shell }}$ are relatively small (compared to soil resistance $R_{\text {soil }}$ or to $R_{\mathrm{BL}}$ for wet conditions) and thus can be neglected.

The evaporation flux from unsaturated soil surface $E_{\text {surf }}$ can thus be simplified (setting $R_{\text {shell }}=0$ ) and relating it to potential rate $E_{0}$ in the following main result of this study (derivation in supporting information $\mathrm{S} 1$ ):

$$
\frac{E_{\text {surf }}}{E_{0}}=\frac{4 K\left(\theta_{\text {surf }}\right)\left[1+E_{0} / 4 K\left(h_{c}\right)\right]}{E_{0}+4 K\left(\theta_{\text {surf }}\right)\left[1+E_{0} / 4 K\left(h_{c}\right)\right]}
$$

Note that we have checked the validity of $K_{\text {eff }}=4 K\left(\theta_{\text {surf }}\right)$ for the water contents at end of stage 1 (defined by the critical pressure $h_{C}$ ), values that are more restrictive than in Haghighi et al. (2013). The ratio $E_{\text {surf }} / E_{0}$ was defined in Merlin et al. (2016) as soil evaporation efficiency (SEE) that will be used in the following. In Figure $1 \mathrm{~b}$, the SEE is plotted as function of water content showing that for fine-textured soils with high resistance to capillary flow, the surface evaporation rate drops rapidly with a decrease in surface water content. 

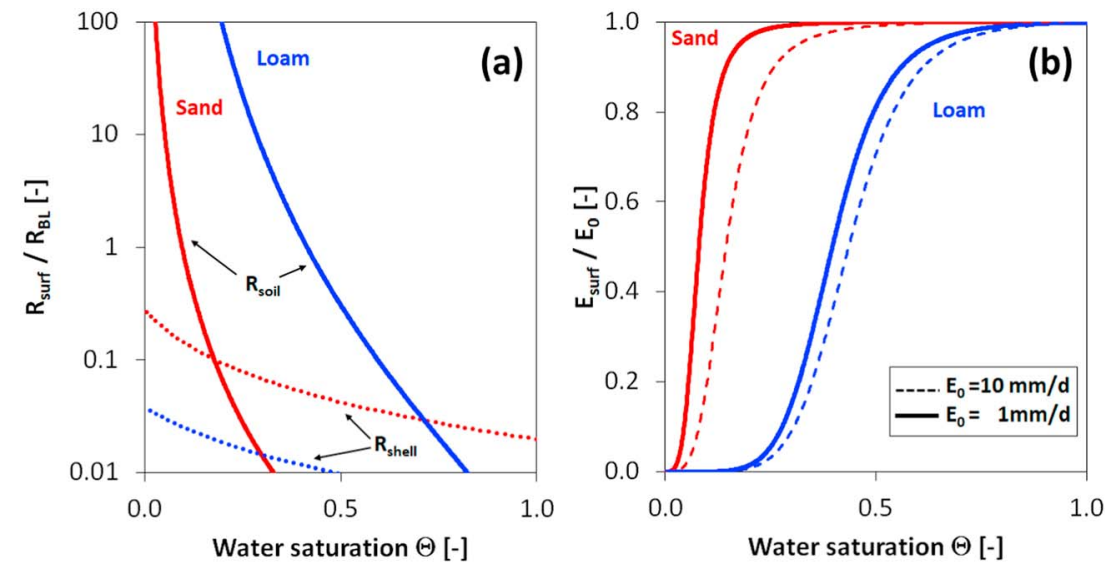

Figure 1. Effect of soil water saturation on evaporation rate from partially dry surface for two different soil textural classes (sand in red and loam in blue). (a) The evaporation rate is controlled by three resistances, assigned to soil water flow (equation (6), $\left.R_{\text {soil }}\right), 3-\mathrm{D}$ diffusion around water-filled pores (equation (4), $\left.R_{\text {shell }}\right)$, and across boundary layer (equation (2b)), $\left.R_{\mathrm{BL}}\right)$. Solid lines show the ratio $R_{\text {soil }} / R_{\mathrm{BL}}$, and the dashed lines show $R_{\text {shell }} / R_{\mathrm{BL}}$ for potential evaporation rate of $2 \mathrm{~mm} /$ day. The values $R_{\text {shell }} / R_{\mathrm{BL}}$ are $<0.1$ for wet conditions, and $\mathrm{R}_{\text {shell }}$ is much smaller than capillary flow resistance $R_{\text {soil }}$ for dry conditions and can be neglected. (b) Ratio between evaporation rate from partially dry surface $E_{\text {surf }}$ and potential rate $E_{0}$ computed with equation (10) for high (dashed line) and low (solid line) potential evaporation rate. For coarse-textured soils and low potential rates the dramatic change in evaporation rate occurs for smaller water saturations.

The measurements reported in Merlin et al. (2016) were used to determine the critical water content $\theta_{1 / 2}$ at which SEE $=1 / 2$. This critical water content can also be determined analytically using the physical model equation (10) by solving (finding the roots of) the following expression for $\theta_{1 / 2}$ using the Mualem (1976) and van Genuchten (1980) model for unsaturated hydraulic conductivity function:

$$
\begin{gathered}
K_{\text {sat }} \sqrt{\Theta_{1 / 2}}\left[1-\left(1-\Theta_{1 / 2}^{1 / m}\right)^{m}\right]^{2}=\frac{E_{0} \cdot K\left(h_{\mathrm{C}}\right)}{E_{0}+4 K\left(h_{\mathrm{C}}\right)} \\
\Theta_{1 / 2}=\frac{\theta_{1 / 2}-\theta_{\text {res }}}{\theta_{\text {sat }}-\theta_{\text {res }}}
\end{gathered}
$$

with the parameter $m=1-1 / n$, residual water content $\theta_{\text {res, }}$ and the saturated water content $\theta_{\text {sat }}$, defining the water saturation $\Theta_{1 / 2}$. We emphasize that the effects of water content and soil texture on surface resistance and consequently on evaporation rates presented in this section are for stage 1 evaporation (the plane of phase change is at the surface) before the onset of stage 2 (the vaporization plane recedes below the surface).

\section{Measurements and Study Sites Description}

To study the relationship between soil water content and evaporation rate we use time series of bare-soil evaporation reported in Merlin et al. (2016) for 34 different sites. For all sites clay and sand fractions were reported, enabling determination of the soil textural class. As shown in Figure 2a the sites span 10 out of the 12 classified soil textural classes. To test the ability of the evaporation resistance model to predict effects of soil texture on measured surface evaporation rates, we have chosen one site for each of the 10 soil textural classes. The evaporation rates were measured using eddy-covariance flux towers that reported values every 30 or 60 min (called hourly values in the following). The critical water content $\theta_{1 / 2}$ of Merlin et al. (2016) was estimated from relatively scattered hourly data, using scaling and data binning. The scaled values can be represented by a smooth curve as shown in Figure $2 \mathrm{~b}$. In Figures $2 \mathrm{c}$ and $2 \mathrm{~d}$ the original hourly values and the scaled smooth curves are shown for two sites. In this study we follow a simpler approach for determining SEE that relies on daily means and employs potential evaporation rate (see details in supporting information S2; Shuttleworth \& Wallace, 1985) computed with the method of Jensen and Haise (1963; the effect of this choice compared to other methods is shown in supporting information S2; Jensen et al., 1970; Maes et al., 2018; Milly \& Dunne, 2016; Monteith, 1965; Penman, 1948; Priestley \& Taylor, 1972; Slatyer \& Mcllroy, 1969). 
(a)
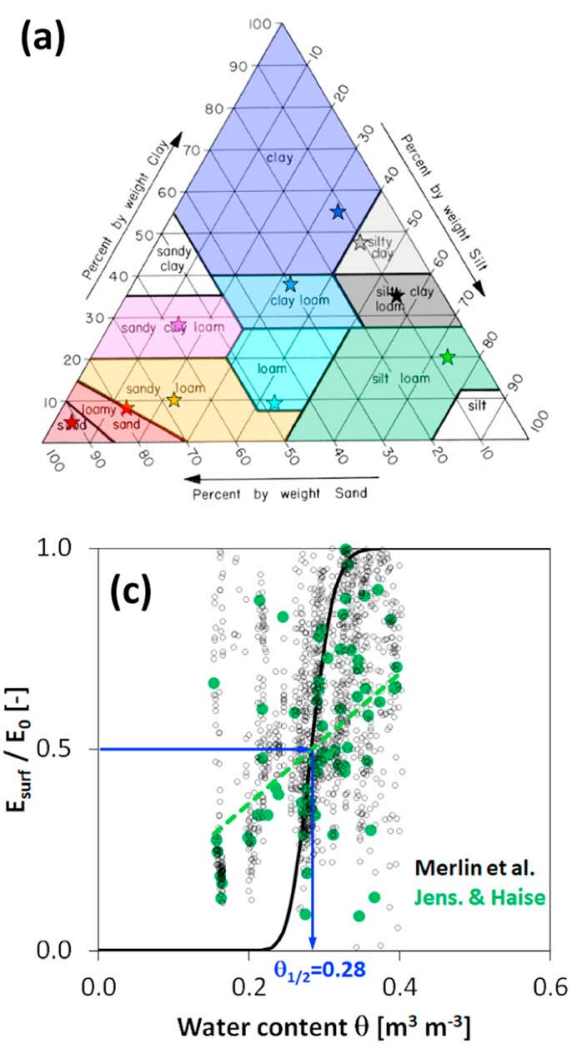
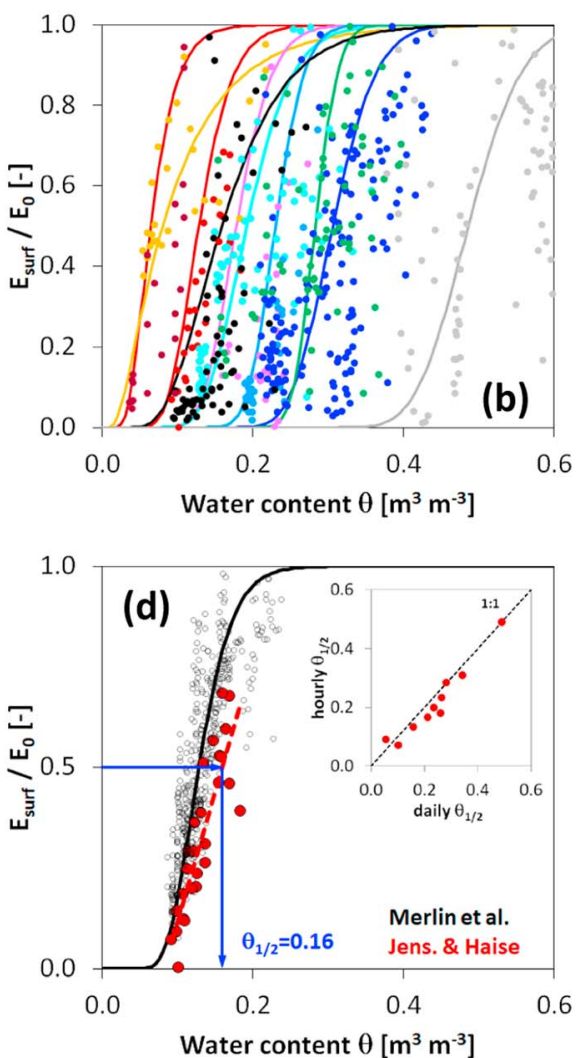

Figure 2. Overview on experimental data used to study soil texture effects on evaporation fluxes. (a) Soil texture triangle with classes covered by data sets marked in different colors. The stars mark the sand, silt, and clay fractions of 10 sites that are presented in panel (b) with soil evaporation efficiency computed on a daily basis (disks) and the lines based on the data processing in Merlin et al. (2016). Panels (a) and (b) show that for finer textures the evaporation efficiency drops for larger water contents. The transition from high to low efficiency can be characterized by the critical water content $\theta_{1 / 2}$ as shown explicitly in panels (c) and (d) for two different textures (silt loam in (c) and loamy sand in (d)). Large colored symbols show values deduced from daily values (potential rates determined with Jensen and Haise (1963)), and the dashed line shows a linear fit. The critical water content $\theta_{1 / 2}$ (where soil evaporation efficiency $=0.5$ ) is determined based on the linear regression line (blue arrows). Small black symbols show hourly values that are used to compute the smooth modeled black lines following the procedure in Merlin et al. (2016). The inset in (d) compares the critical water content values $\theta_{1 / 2}$ obtained with the two different procedures.

For conditions with low evaporative demand (here smaller than $2 \mathrm{~mm} /$ day) the resulting values of SEE and potential rate showed considerable scatter, as those were not limited by soil water content but rather by energy availability, and were thus excluded from this analysis. In Figure 2 the SEE computed for daily values are shown and compared to the procedure of Merlin et al. (2016) with hourly values. The critical water content $\theta_{1 / 2}$ was deduced from linear regression of the (daily) pairs $(S E E, \theta)$ and inserting the value $S E E=0.5$ in the linear equation. In the inset of Figure $2 d$ the critical values $\theta_{1 / 2}$ are compared for the two procedures and show good agreement.

To model SEE using equation (10) we need estimates of soil hydraulic properties of each soil type. We determine the hydraulic functions using a pedotransfer function (Schaap et al., 2001) with measured sand and clay fractions as inputs (Table S3; Tóth et al., 2015). Due to the extreme sensitivity of the hydraulic properties to differences in soil texture (and soil structure) that may vary in space, we injected a spread in these properties to the estimates of SEE by varying hydraulic functions of the same textural classes.

\section{Results}

The physically based model for estimating SEE using equation (10) was applied to the 10 soil textural classes (Figure 3). For all soil textures, we observed a sharp decrease of SEE when surface water content dropped below a critical value. The coarser the soil texture, the lower the critical water content value for the drop in 

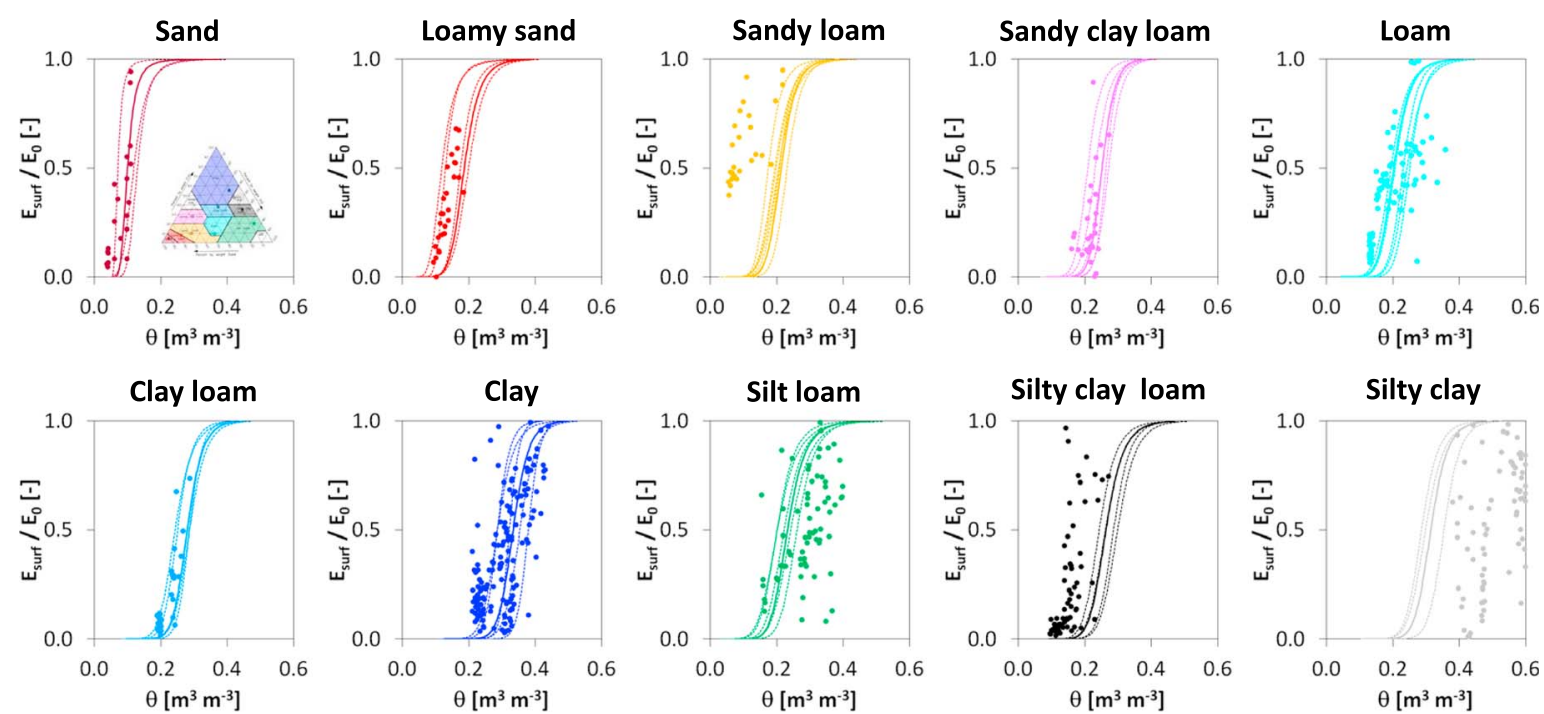

Figure 3. Comparison between measured soil evaporative efficiency (ratio between actual soil evaporation rate $E_{\text {surf }}$ and potential evaporation rate $E_{0}$ ) and predictions based on equation (10) for the 10 different soil textural classes (see inset at the top left of the figure). The symbols show daily values deduced from time series. The bold solid line shows predictions for the hydraulic functions using measured sand and clay fraction. To show variability of model outcome, predictions are presented for a range of other hydraulic functions of the same textural class (dashed lines). The model results are shown for the average potential evaporation rate of each site (between 4 and $8 \mathrm{~mm} /$ day) but are not very sensitive to the chosen value if it is the same order of magnitude.

SEE. The results suggest that for "conductive coarse soils" capillary flows become limiting at much lower water contents than in fine-textured soils, with smaller conducting pores, where capillary flow becomes limiting under wetter conditions. The onset of evaporation limitations at lower water contents in coarsetextured soils is attributed to the shape of the hydraulic conductivity function (as described in supporting information S3), namely, the higher values of hydraulic conductivity for coarse soils for the entire water saturation range.

For most soil textural classes (6 out of 10 in Figure 3), model predictions were in very good agreement with measurements of the changes in evaporation efficiency with surface water content. For sandy loam and silt clay loam the model overestimates the water content where the change in SEE occurs, and it underestimates the transition water content for silt loam and silt clay. To check if the deviation is systematic for a certain soil type we repeated the analyses for other sites of the same soil textural class and obtained better agreement and no systematic trend to larger or smaller values (see supporting information S3). The results show that the behavior is very sensitive to the estimates of the hydraulic functions (i.e., the relationship between water content, capillary pressure, and hydraulic conductivity) that are inferred solely from textural information; other factors such as soil structure may be important but are unknown for these sites.

To assess the predictive power of the model approach we compare in Figure 4 the critical water content $\theta_{1 / 2}$ retrieved from the measured data with predictions based on the resistance model and its solution for SEE $=1 / 2$ given in equations (11a) and (11b). For a more complete overview on model performance we compared all 34 sites (parameter values of hydraulic functions are given in supporting information $\mathrm{S} 3$ ). In Figure 4a the measured $\theta_{1 / 2}$ values and the physically based predictions of $\theta_{1 / 2}$ are compared. The values are scattered around the 1:1 line, but the measured water content value is clearly underestimated for three fine-textured soils with measured water contents close or even higher than the saturated water content estimated by pedotransfer function. More information on measured water content and hydraulic conductivity under saturated conditions would be important to see if the deviation by the model are caused by underestimated $\theta_{\text {sat }}$ and $K_{\text {sat }}$ values.

To illustrate the effects of soil texture on the value of $\theta_{1 / 2}$, Merlin et al. (2016) fitted the following empirical relationship to their inferred values:

$$
\theta_{1 / 2}=0.20+0.28 f_{\text {clay }}-0.16 f_{\text {sand }}
$$

with sand and clay fractions $f_{\text {sand }}$ and $f_{\text {clay. }}$. In Figure $4 \mathrm{~b}$ we compare critical water contents $\theta_{1 / 2}$ computed with this empirical relationship, equation (12), with predictions from the physical model, equation (11a) 

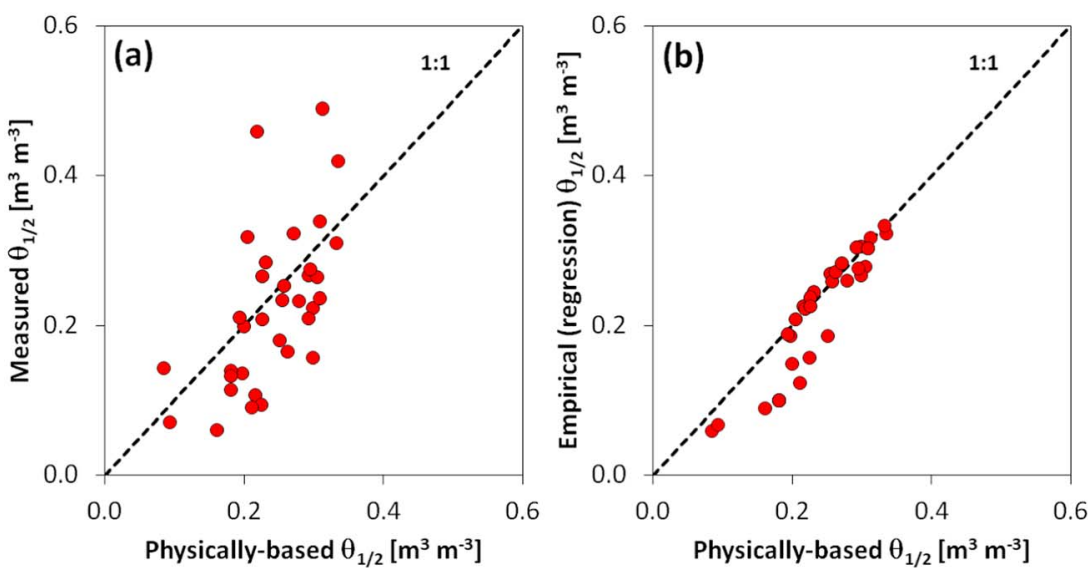

Figure 4. Comparison of predicted critical water content $\theta_{1 / 2}$ (soil evaporative efficiency is 0.5 ) with values reported in Merlin et al. (2016) for 34 bare-soil sites. (a) The physically based predictions using equations (11a) and (11b) are compared to the values retrieved from measurements. For three fine-textured soils (measured $\theta_{1 / 2}$ above 0.4 ) the water contents are underestimated by the physically based model. (b) The effect of soil texture on $\theta_{1 / 2}$ was described by a linear regression in Merlin et al. (2016; equation (12) in this study). The physically based predictions are in good agreement with this regression model fitted to measured values, confirming that the new model successfully reproduces measured textural effects on evaporation dynamics.

and (11b). The figure shows that the "fitted" (empirical regression to measured $\theta_{1 / 2}$ data) and "predicted" values are very similar. This means that the physical model (equation (11a)) predicts successfully measured effects of soil texture on critical water content affecting transition in evaporation rate.

\section{Summary and Conclusions}

SEE (ratio of soil to potential evaporation rate) is a nonlinear function of surface water content that exhibits a sharp decrease at a critical water content, $\theta_{1 / 2}$. In this study we provide a physically based surface resistance model (Haghighi et al., 2013; Lehmann et al., 2008) to represent the critical role of capillary flow resistance, which varies with soil textures and defines soil ability to supply water to an evaporation surface. Results of the physical model are in good agreement with observations (Merlin et al., 2016). The main conclusions of this letter are as follows:

1. Capillary viscous flow effects become limiting and constrain surface evaporation rate at low soil moisture contents;

2. Capillary flow limitations are more pronounced in fine-textured soils (coarse soils have higher hydraulic conductivities for the same water content);

3. When capillary flow limitations become dominant, surface evaporation decreases even while main vaporization plane remains at the surface (the drop in SEE is not necessarily due to receding vaporization plane in stage 2);

4. The response to water content limitation is very abrupt across soil textures; and

5. The use of soil hydraulic properties (estimated with a pedotransfer function) in a physical modeling framework (equation (11a)) offers predictability of SEE behavior and estimate $\theta_{1 / 2}$ for all soil textures.

The study highlights the importance of soil texture on the dynamics of surface evaporation as a function of surface content and offers a physically based framework for including this nonlinear dependence in a simple resistance model to be used in land-surface model or remote sensing estimates.

Acknowledgments

Data are available on repository (https://figshare.com/s/

f28146e8cc34795ef40b). The original bare-soil data set was prepared in the frame of the MIXMOD-E project (ANR13-JS06-0003). Gentine acknowledges funding from NASA NNH17ZDA0OINTHP.

\section{References}

Allen, R. G., Pereira, L. S., Raes, D., \& Smith, M. (1998). Crop evapotranspiration: Guidelines for computing crop requirements. Irrigation and Drainage Paper No. 56, FAO, Rome, Italy.

Bange, G. G. J. (1953). On the quantitative explanation of stomatal transpiration. Acta Botanica Neerlandica, 2(3), 255-297. https://doi.org/ 10.1111/j.1438-8677.1953.tb00275.x

Bittelli, M., Ventura, F., Campbell, G. S., Snyder, R. L., Gallegati, F., \& Pisa, P. R. (2008). Coupling of heat, water vapor, and liquid water fluxes to compute evaporation in bare soils. Journal of Hydrology, 362(3-4), 191-205. https://doi.org/10.1016/j.jhydrol.2008.08.014

Budyko, M. I. (1958). The heat balance of the Earth's surface (p. 259). Washington, DC: U.S. Department of Commerce, Weather Bureau. 
Decker, M., Or, D., Pitman, A., \& Ukkola, A. (2017). New turbulent resistance parameterization for soil evaporation based on a pore-scale model: Impact on surface fluxes in CABLE. Journal of Advances in Modeling Earth Systems, 9, 220-238. https://doi.org/10.1002/ 2016MS000832

Fisher, J. B., Melton, F., Middleton, E., Hain, C., Anderson, M., Allen, R., et al. (2017). The future of evapotranspiration: Global requirements for ecosystem functioning, carbon and climate feedbacks, agricultural management, and water resources. Water Resources Research, 53, 2618-2626. https://doi.org/10.1002/2016WR020175

Guarracino, L. (2007). Estimation of saturated hydraulic conductivity Ks from the van Genuchten shape parameter $\alpha$. Water Resources Research, 43, W11502. https://doi.org/10.1029/2006WR005766

Haghighi, E., Shahraeeni, E., Lehmann, P., \& Or, D. (2013). Evaporation rates across a convective air boundary layer are dominated by diffusion. Water Resources Research, 49, 1602-1610. https://doi.org/10.1002/wrcr.20166

Jensen, M. E., \& Haise, H. R. (1963). Estimating evapotranspiration from solar radiation. Proceedings of the American Society of Civil Engineers. Journal of the Irrigation and Drainage Division, 89, 15-41.

Jensen, M. E., Robb, D. C. N., \& Franzoy, C. E. (1970). Scheduling irrigations using climate-cropsoil data. Journal of the Irrigation and Drainage Division, 96, 25-38.

Lee, T. J., \& Pielke, R. A. (1992). Estimating the soil surface specific humidity. Journal of Applied Meteorology, 31(5), 480-484. https://doi.org/ 10.1175/1520-0450(1992)031<0480:ETSSSH >2.0.CO;2

Lehmann, P., Assouline, S., \& Or, D. (2008). Characteristic lengths affecting evaporative drying of porous media. Physical Review E, 77(5), 056309. https://doi.org/10.1103/PhysRevE.77.056309

Maes, W. H., Gentine, P., Verhoest, N. E. C., \& Miralles, D. G. (2018). Potential evaporation at eddy-covariance sites across the globe. Hydrology and Earth System Sciences Discussions, 1-33. https://doi.org/10.5194/hess-2017-682

Manabe, S. (1969). Climate and the ocean circulation I. The atmosphere and the hydrology of the Earth's surface. Monthly Weather Review, 97 739-774.

Martens, B., Miralles, D. G., Lievens, H., van der Schalie, R., de Jeu, R. A., Fernández-Prieto, D., \& Verhoest, N. E. (2017). GLEAM v3: Satellitebased land evaporation and root-zone soil moisture. Geoscientific Model Development, 10(5), 1903-1925. https://doi.org/10.5194/gmd-101903-2017

Merlin, O., Stefan, V. G., Amazirh, A., Chanzy, A., Ceschia, E., Er-Raki, S., et al. (2016). Modeling soil evaporation efficiency in a range of soil and atmospheric conditions using a meta-analysis approach. Water Resources Research, 52, 3663-3684. https://doi.org/10.1002/2015WR018233

Milly, P. C. D., \& Dunne, K. A. (2016). Potential evapotranspiration and continental drying. Nature Climate Change, 6(10), 946-949. https://doi. org/10.1038/nclimate3046

Miralles, D. G., Jiménez, C., Jung, M., Michel, D., Ershadi, A., McCabe, M. F., et al. (2016). The WACMOS-ET project—Part 2: Evaluation of global terrestrial evaporation data sets. Hydrology and Earth System Sciences, 20(2), 823-842. https://doi.org/10.5194/hess-20-823-2016

Monteith, J. L. (1965). Evaporation and environment. Symposia of the Society for Experimental Biology, 19, $205-234$.

Mualem, Y. (1976). A new model for predicting the hydraulic conductivity of unsaturated porous media. Water Resources Research, 12(3), 513-522. https://doi.org/10.1029/WR012i003p00513

Or, D., Lehmann, P., Shahraeeni, E., \& Shokri, N. (2013). Advances in soil evaporation physics-A review. Vadose Zone Journal, 12(4), 1-16. https://doi.org/10.2136/vzj2012.0163

Penman, H. L. (1948). Natural evaporation from open water, bare soil and grass. Proceedings of the Royal Society of London A, 193(1032), 120-145. https://doi.org/10.1098/rspa.1948.0037

Philip, J. R., \& de Vries, D. A. (1957). Moisture movement in porous materials under temperature gradients. Eos, Transactions American Geophysical Union, 38(2), 222-232. https://doi.org/10.1029/TR038i002p00222

Phillips, T. J., Klein, S. A., Ma, H. Y., Tang, Q., Xie, S., Williams, I. N., et al. (2017). Using ARM observations to evaluate climate model simulations of land-atmosphere coupling on the US Southern Great Plains. Journal of Geophysical Research: Atmospheres, 122, 11,524-11,548. https:// doi.org/10.1002/2017JD027141

Priestley, C., \& Taylor, R. (1972). On the assessment of surface heat flux and evaporation using large-scale parameters. Monthly Weather Review, 100(2), 81-92. https://doi.org/10.1175/1520-0493(1972)100<0081:OTAOSH >2.3.CO;2

Schaap, M. G., Leij, F. J., \& Van Genuchten, M. T. (2001). Rosetta: A computer program for estimating soil hydraulic parameters with hierarchical pedotransfer functions. Journal of Hydrology, 251(3-4), 163-176. https://doi.org/10.1016/S0022-1694(01)00466-8

Schlünder, E. U. (1988). On the mechanism of the constant drying rate period and its relevance to diffusion controlled catalytic gas phase reactions. Chemical Engineering Science, 43(10), 2685-2688. https://doi.org/10.1016/0009-2509(88)80012-5

Shahraeeni, E., Lehmann, P., \& Or, D. (2012). Coupling of evaporative fluxes from drying porous surfaces with air boundary layer: Characteristics of evaporation from discrete pores. Water Resources Research, 48, W09525. https://doi.org/10.1029/2012WR011857

Shuttleworth, W. J., \& Wallace, J. S. (1985). Evaporation from sparse canopies-an energy combination theory. Quarterly Journal of the Royal Meteorological Society, 111(469), 839-855. https://doi.org/10.1002/qj.49711146910

Slatyer, R., \& Mcllroy, I. (1969). Practical micrometeorology. Paris: UNESCO.

Suzuki, M., \& Maeda, S. (1968). On the mechanism of drying of granular beds, mass transfer from discontinuous source. Journal of Chemical Engineering of Japan, 1(1), 6. https://doi.org/10.1252/jcej.1.26

Tóth, B., Weynants, M., Nemes, A., Maó, A., Bilas, G., \& Tóth, G. (2015). New generation of hydraulic pedotransfer functions for Europe. European Journal of Soil Science, 66(1), 226-238. https://doi.org/10.1111/ejss.12192

van de Griend, A. A., \& Owe, M. (1994). Bare soil surface resistance to evaporation by vapor diffusion under semiarid conditions. Water Resources Research, 30(2), 181-188. https://doi.org/10.1029/93WR02747

van Genuchten, M. T. (1980). A closed-form equation for predicting the hydraulic conductivity of unsaturated soils. Soil Science Society of America Journal, 44(5), 892-898. https://doi.org/10.2136/sssaj1980.03615995004400050002x

Wallace, J. S. (1995). Calculating evaporation: Resistance to factors. Agricultural and Forest Meteorology, 73, 353-366.

Wei, Z., Yoshimura, K., Wang, L., Miralles, D. G., Jasechko, S., \& Lee, X. (2017). Revisiting the contribution of transpiration to global terrestrial evapotranspiration. Geophysical Research Letters, 44, 2792-2801. https://doi.org/10.1002/2016GL072235

Wetzel, P. J., \& Chang, J.-T. (1987). Concerning the relationship between evapotranspiration and soil moisture. Journal of Climate and Applied Meteorology, 26(1), 18-27. https://doi.org/10.1175/1520-0450(1987)026<0018:CTRBEA > 2.0.CO;2

Wythers, K. R., Lauenroth, W. K., \& Paruelo, J. M. (1999). Bare-soil evaporation under semiarid field conditions. Soil Science Society of America, 63(5), 1341-1349. https://doi.org/10.2136/sssaj1999.6351341x

Yamanaka, T., \& Yonetani, T. (1999). Dynamics of the evaporation zone in dry sandy soils. Journal of Hydrology, 217(1-2), 135-148. https://doi. org/10.1016/S0022-1694(99)00021-9

Zhang, C., Li, L., \& Lockington, D. (2015). A physically based surface resistance model for evaporation from bare soils. Water Resources Research, 51, 1084-1111. https://doi.org/10.1002/2014WR015490 